\title{
Force-deflection behavior of piezoelectric C-block actuator arrays
}

\author{
Andrew J Moskalik $\dagger$ and Diann Brei $\ddagger$ \\ $\dagger$ U.S. EPA—National Vehicle and Fuel Emissions Lab, 2000 Traverwood Drive, Ann Arbor, \\ MI 48105, USA \\ \$ Department of Mechanical Engineering and Applied Mechanics, 2250 G G Brown Building, \\ 2350 Hayward Street, The University of Michigan, Ann Arbor, MI 48109-2125, USA
}

Received 29 September 1998, in final form 12 July 1999

Abstract. C-blocks are unique piezoelectric building blocks which can be combined in
series or parallel to generate tailorable performance and exploit the advantages of bender and
stack architectures. This paper presents a complete theoretical model that predicts the
force-deflection behavior for any generic C-block actuator array configuration.
An experimental investigation with five case studies is described that validates the model over
a broad range of actuator prototypes and performance. This study characterizes the sensitivity
of this class of actuator array with respect to material, geometric, and configuration
parameters. The paper concludes with a comparison of the generic C-block architecture to the
current state of art on a basis of absolute measures such as maximum force, deflection, and
work and normalized measures such as effective stress, strain, and work per actuator volume.
From this, it is concluded that C-blocks are a highly efficient, mid-range actuation technology.

\section{Introduction}

Many smart structure applications need actuators that can simultaneously supply adequate levels of force and deflection while fitting into constrained application spaces. Smart materials such as shape memory alloys, magnetostrictives, electrostrictives, and piezoelectrics have great potential to meet this need due to their high energy density. Unfortunately, each material has its drawbacks. For example, shape memory alloys have slow response times, and electro- and magnetostrictives have a nonlinear response. Piezoelectric materials are often chosen for smart structure applications because of their good dynamic response and fairly linear behavior. However, the displacements required for a given application are often difficult to obtain directly from monolithic blocks of piezoelectric material because of the relatively small strain produced by the material.

To increase the displacement generated by piezoelectric material, different actuator architectures have been invented. For example, stacks (Spencer and Chopra 1996) increase overall actuator deflection by adding the deflections of constituent layers of piezoelectric material. Although stacks produce large forces, the overall deflection obtainable is still relatively small. To further increase deflection, a common approach is to augment the output of the stack by utilizing external mechanical leveraging systems to improve deflection performance at the expense of force generation capability (Bamford et al 1995, Samak and Chopra 1996). Several novel types of actuators (figure 1), such as the X-frame (Prechtl and Hall 1997), Moonie (Onitsuka et al 1995), and Cymbal (Dogan et al 1997), take advantage of external leveraging elements to increase the displacement available from monolithic or stack piezoelectric actuators. Unfortunately, leveraging of stacks frequently suffers from transmission losses of a factor of three to five (Paine and Chaudhry 1996) and may create difficulties in packaging the additional external leveraging mechanisms.

As an alternative to external leveraging, some common piezoelectric actuator architectures such as straight benders use internal leveraging. Straight benders can be of constant cross section (Ben-Zeev and Chopra 1996) as shown in figure 2(a), or tapered cross section (Hall and Prechtl 1996) as shown in figure $2(b)$. Other types of internally leveraged actuators include Rainbow actuators (Haertling 1994) as shown in figure 2(c), and similar architectures such as Cerambows (Kugel et al 1997), CRESCENTs (Chandran et al 1997), and THUNDERs (Face International 1997). The work output of these actuators is smaller than that of a similarly sized straight bender actuators by $15 \%$ to over $90 \%$ (Kugel et al 1997). Even though all of these benders generate large deflections, the forces are unfortunately small. In addition, these bender architectures produce deflection transverse to the length of the actuator package, which can be a problem in some applications.

One approach that combines the stack and bender concepts is a C-block (Brei et al 1996, Moskalik and Brei 1997a, b, 1998). C-blocks are a bender similar in nature to straight benders, but their $\mathrm{C}$-shape facilitates combination into serial configurations similar to stacks. An individual C-block is constructed from semicircular piezoelectric material poled in the radial direction and activated in the circumferential direction by a voltage applied across the thickness (figure $2(d)$ ). The piezoelectric strain produced creates a bending moment within the individual 


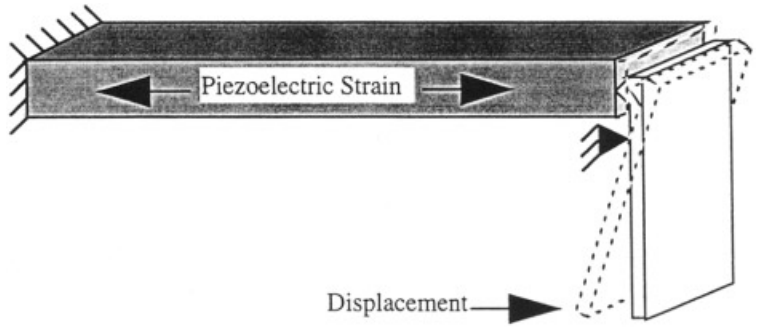

(a)

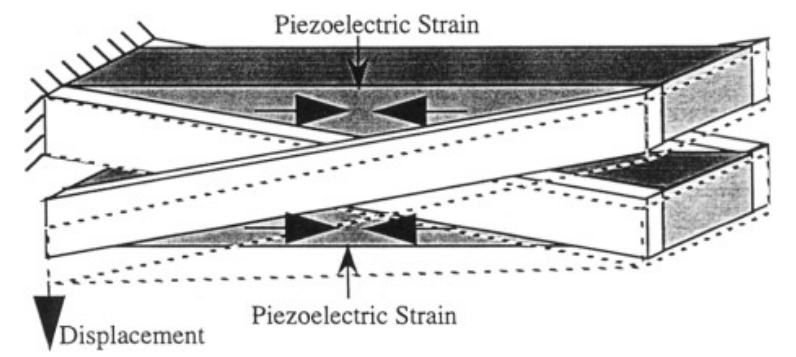

(b)

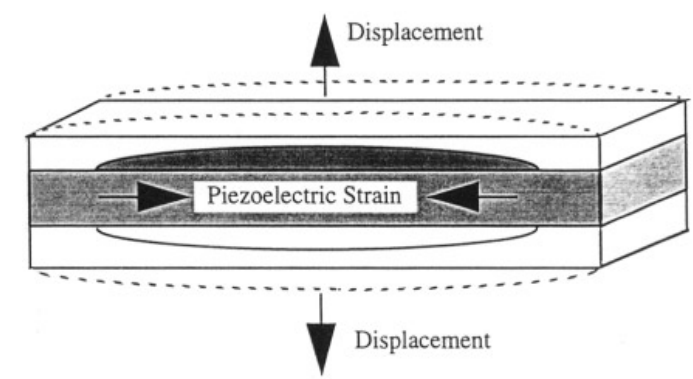

(c)

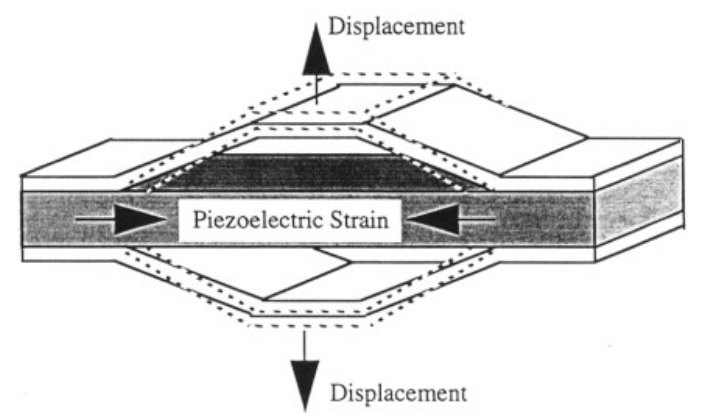

(d)

Figure 1. Externally leveraged piezoelectric actuator architectures. Many actuator architectures have been developed to increase the deflection output of piezoelectric material. Some of these piezoelectric actuator architectures rely on external

leveraging, such as the $(a)$ leveraged stack, $(b) \mathrm{X}$-frame actuator, $(c)$ Moonie actuator and $(d)$ Crescent actuator.

C-block, similar to straight benders, which causes the entire actuator architecture to flex. Individual C-blocks are capable of generating over twice the force of a straight bender with a slight reduction in deflection (Moskalik and Brei 1997b). To compensate for this loss of deflection, individual C-blocks can be combined in series to increase the total output deflection without impact on the force generation. This is similar to a stack which combines monolithic material in series; however, in this case the tip deflection of the C-block series is significantly greater than that of a stack confined to the same application space. In addition, C-blocks can

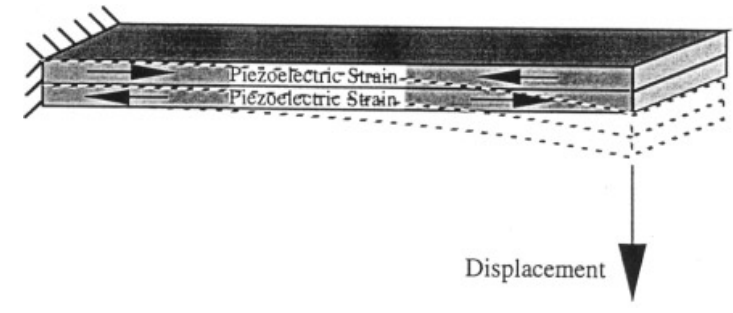

(a)

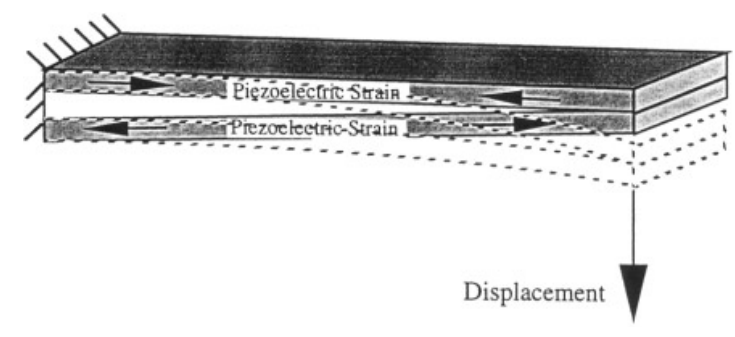

(b)

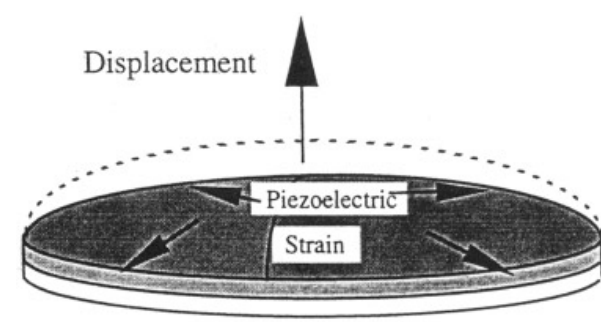

$(c)$

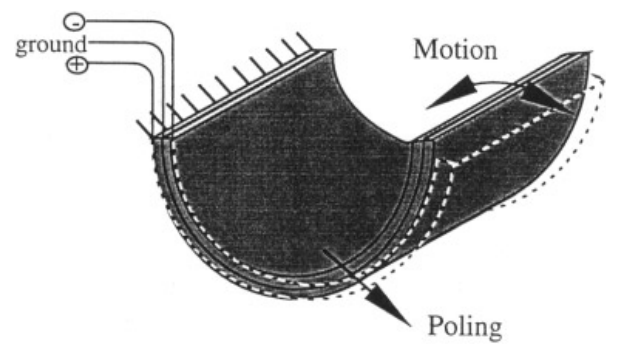

$(d)$

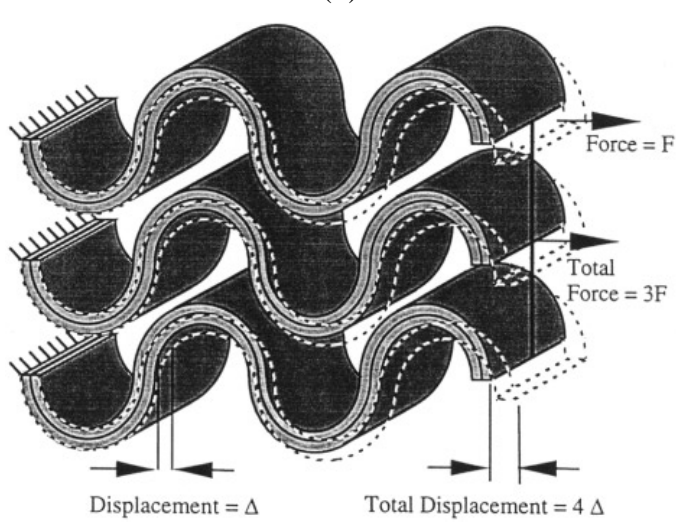

(e)

Figure 2. Internally leveraged piezoelectric actuator architectures. Other architectures rely on internal leveraging, such as the (a) straight bender, $(b)$ tapered bender and (c) Rainbow-type actuator, which includes the Cerambow, CRESCENT, and THUNDER. $(d)$ The individual C-block actuator and its deflection operation. (e) The C-block array is comprised of $n$ identical individual C-blocks in series and $m$ in parallel, driven with an internal piezoelectric moment of alternating sign. This results in an overall increase in the length of the C-block series equal to the linear sum of the individual C-blocks. 
be added in parallel to increase force output without loss of deflection. By being able to add discrete C-blocks in both series and parallel, as shown in figure $2(e)$, additional design freedoms are gained; thus, it is easier to directly tailor the performance of the solid state actuator to an application with a constrained volume.

Past characterization of this unique architecture has included the force-deflection performance of an individual C-block (Moskalik and Brei 1997b) and the deflection performance of serial C-block actuators (Moskalik and Brei 1998). However, the previous work has not included the complete force-deflection characterization of a generic C-block array. Without this, design and prediction of the performance of C-block arrays is not possible for highforce applications, such as vibration damping of helicopter rotor blades, shaping of aerodynamic surfaces, and injection of high pressure fuel, which require force generation from a serial or array configuration. This paper presents the complete characterization of the force-deflection behavior of a generic piezoelectric C-block actuator array. A fundamental theoretical model is derived to predict the quasistatic performance of any C-block array configuration. To verify the model, five case studies were experimentally tested using both piezoceramic and polymeric materials, and the results were analyzed to determine the sensitivity of the actuator design to the geometric, material and architecture parameters. The validated model is used to compare C-blocks to the current state of the art of piezoelectric actuators to assess where this architecture is most useful.

\section{Theoretical force-deflection model derivation}

The theoretical model for the quasi-static force-deflection model of the serial C-block was derived to provide a simple prediction of the behavior of serial C-blocks for use by application engineers. The nomenclature used in the derivation of this model is given in figure 3 , where $\Delta$ is the tip deflection, $R_{n}$ is the neutral axis radius, $b$ is width, $z$ is distance from the neutral axis to the outside of a layer, and $F_{\Delta}$ is the load applied at the C-block tip in the direction of the tip deflection. During the derivation, the C-block array was assumed to be comprised of $n$ identical individual piezoelectric C-blocks in series and $m$ in parallel. Each individual C-block was assumed to be a thin, perfectly bonded laminate curved beam with $q$ layers, including piezoelectric, bonding, electrode, and substrate layers. Additionally, the polarity of the piezoelectric C-block material and the applied voltage field is assumed to be such that the tip deflections of the individual C-blocks add together, and thus the signs of the internal piezoelectric moments alternate as shown in figure 3 .

The model was derived by determining the strain energy stored in an individual C-block, summing the energy for all C-blocks in the array, and applying Castigliano's theorem to derive the quasi-static force-deflection model. The complementary strain energy, $U^{*}$, contained in each individual C-block making up the array is a function of the internal moment within the C-block. The internal moment at any angular position, $\theta$, is the sum of the piezoelectric moment, $M^{P}$, and the moment induced by the applied load,
$F_{\Delta} / m$, where the force $F_{\Delta}$ has been evenly divided among the $m$ sets of C-blocks in parallel. Depending on the position of the C-block within the array, the expression for the total moment differs due to the alternating internal piezoelectric moment and geometric position of the C-block, with the oddnumbered C-blocks being positive and the even-numbered C-blocks being negative,

$$
M= \pm\left(M^{P}+\frac{F_{\Delta}}{m} R_{n} \sin \theta\right) .
$$

The strain energy within one C-block can be derived by squaring the internal moment (1), dividing by the composite bending stiffness, $D$, and integrating along the length of the C-block. Since the moment is squared, both odd and even C-blocks have the same strain energy,

$$
U^{*}=\int_{0}^{\tau} \frac{\left(M^{P}+\left(F_{\Delta} / m\right) R_{n} \sin \theta\right)^{2}}{2 D} R_{n} \mathrm{~d} \theta .
$$

The piezoelectric moment, $M^{P}$, and composite bending stiffness, $D$, are calculated by integrating the internal moment across the cross sectional area of a generic C-block of $q$ layers (Moskalik and Brei 1997a),

$$
M=\sum_{i=1}^{q} b_{i} \int Y_{i}\left[z \kappa-\left(d_{31} E_{3}\right)_{i}\right] z \mathrm{~d} z=D \kappa-M^{P}
$$

and relating the result to the change in curvature during bending, $\kappa$. In (3), $Y$ is the Young's modulus, $d_{31}$ is the piezoelectric constant, $E_{3}$ is the applied voltage, $b$ is the width, and the subscript $i$ refers to the $i$ th layer. The piezoelectric moment is defined as,

$$
M^{P}=\sum_{i=1}^{q} \frac{1}{2} Y_{i} b_{i}\left(d_{31} V\right)_{i}\left(z_{i}+z_{i-1}\right)
$$

and the composite bending stiffness is defined as,

$$
D=\sum_{i=1}^{q} \frac{1}{3} Y_{i} b_{i}\left(z_{i}^{3}-z_{i-1}^{3}\right) .
$$

The C-block is assumed thin such that the electric field, $E_{3}$, within the $i$ th layer is the voltage, $V$, divided by the thickness, $\left(z_{i}-z_{i-1}\right)$. Since the strain energy within each individual C-block is identical, the total strain energy contained in the array is the number of C-blocks in the array, $n m$, multiplied by the strain energy within one C-block (2),

$$
U^{*}=n m \int_{0}^{\pi} \frac{\left(M^{P}+\left(F_{\Delta} / m\right) R_{n} \sin \theta\right)^{2}}{2 D} R_{n} \mathrm{~d} \theta .
$$

Utilizing Castigliano's theorem and differentiating the total strain energy (6) with respect to $F_{\Delta}$ results in,

$$
\begin{aligned}
\Delta & =\frac{\partial U^{*}}{\partial F_{\Delta}} \\
& =n m \int_{0}^{\pi} \frac{\left(M^{P} / m\right) R_{n}^{2} \sin \theta+\left(F_{\Delta} / m^{2}\right) R_{n}^{3} \sin ^{2} \theta}{D} \mathrm{~d} \theta
\end{aligned}
$$

where $\Delta$ is the tip deflection. Performing the integration in (7) results in a force-deflection model of

$$
\Delta=\frac{\pi n F_{\Delta} R_{n}^{3}}{2 m D}-\frac{2 n M^{P} R_{n}^{2}}{D}
$$




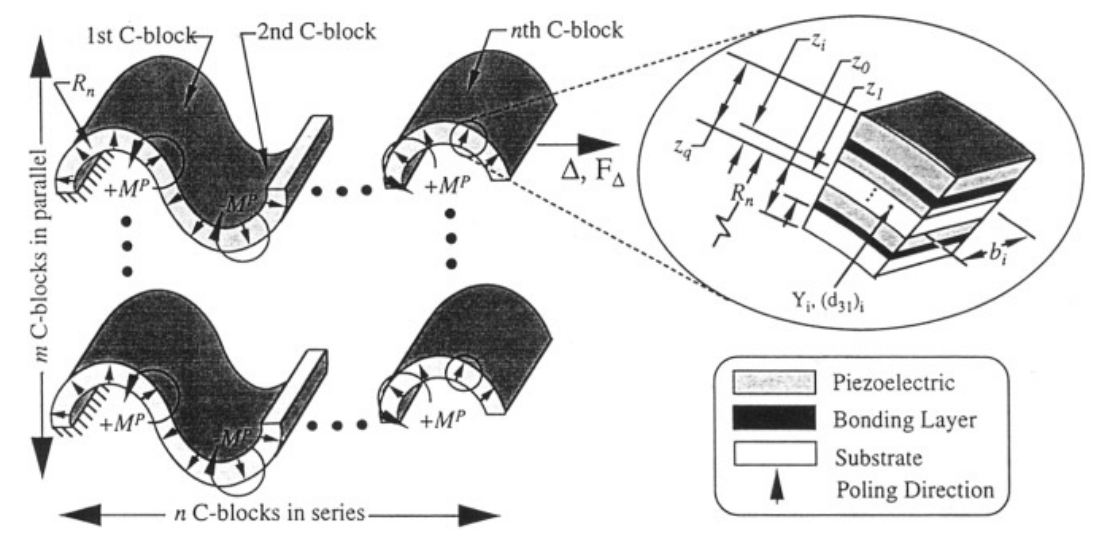

Figure 3. Nomenclature used in derivation of the model. The series C-block is comprised of $n$ individual C-blocks, each having a neutral axis of $R_{n}$ and $q$ composite layers of width $b$ at a distance $z$ from the neutral axis. Each individual C-block has the same cross section, which can include piezoelectric, bonding, and substrate layers. The piezoelectric layers in each C-block are driven to produce a moment $M^{P}$ of alternating sign, such that the tip displacements add.

which relates the tip deflection, $\Delta$, and the applied force, $F_{\Delta}$, to the number of C-blocks in series, $n$, the number in parallel, $m$, and the geometric and material parameters of radius, $R_{n}$, bending stiffness, $D$, and internal moment, $M^{P}$. Substituting in the expressions for moment and bending stiffness for a generic cross section, the model can be explicitly written in terms of geometric parameters, material parameters, and applied voltage, $V$, as

$$
\begin{aligned}
\Delta= & \frac{\pi n R_{n}^{3}}{2 m \sum_{i=1}^{q} Y_{i} b_{i}\left(z_{i}^{3}-z_{i-1}^{3}\right)} F_{\Delta} \\
& -\frac{3 n R_{n}^{2} \sum_{i=1}^{q} Y_{i} b_{i}\left(d_{31} V\right)_{i}\left(z_{i}+z_{i-1}\right)}{\sum_{i=1}^{q} Y_{i} b_{i}\left(z_{i}^{3}-z_{i-1}^{3}\right)}
\end{aligned}
$$

The model derived in (8) can be simplified to find the free deflection, $\Delta_{f}$, by setting the applied force to zero,

$$
\Delta_{f}=-\frac{2 n M^{P} R_{n}^{2}}{D} .
$$

This model predicts that the total free deflection of the array is a linear addition of the deflections of the individual C-blocks in series. Moreover, this displacement does not depend on the number of C-blocks in parallel. Thus, the total displacement of a serial C-block actuators can be increased by adding C-blocks to the series, and the total displacement is simply proportional to the number of C-blocks in series.

The blocked force, $F_{b}$, can be found by setting the deflection to zero,

$$
F_{b}=\frac{4 m M^{P}}{\pi R_{n}} .
$$

This model predicts that the blocked force is a linear function of the number of C-blocks in parallel, and does not depend on the number of C-blocks in the series. Therefore, additional C-blocks can be added to serial actuators, increasing deflection, with no penalty in force production.

The stiffness of the actuator, $k$, can be determined by setting the internal moment, $M^{P}$, to zero and determining the ratio of the force to the deflection,

$$
k=\frac{F_{\Delta}}{\Delta}=\frac{2 m D}{\pi n R_{n}^{3}} .
$$

As is expected from examining the free deflection (10) and the blocked force (12), the stiffness of the serial C-block actuator is inversely dependent on the number of individual C-blocks in the series, $n$ and directly dependent on the number in parallel, $m$. This dependence allows the C-block actuator to be easily tailored to match the stiffness of the application (Giurgiutiu et al 1996).

\section{Experimental investigation}

To validate the force-deflection model and investigate the performance sensitivity of series-C-block actuators, an experimental investigation was conducted by examining five different case studies. The prototypes for these case studies were constructed from two different materials, PZT-5H piezoceramic (where PZT is lead zirconate titanate) and polyvinylidene fluoride $(\mathrm{PVdF})$ polymeric piezoelectric material. The PZT-5H material used to construct the prototypes was chosen for the ceramic prototypes because this material is a commonly used material in smart structures and was readily available commercially. PVdF was chosen for the polymeric prototypes because it can be used to produce prototypes of substantially different geometric and material properties than the piezoceramic material and is a relatively inexpensive material. The following case studies were evaluated to determine how well the model predicted the observed performance over a range of C-block array configurations and to investigate the effect of different design parameters on the static behavior.

- Case study 1 . The first case study, consisting of a series of two polymeric C-blocks, served as a baseline for the polymeric prototypes. This prototype was the simplest configuration containing multiple C-blocks.

- Case study 2. The second case study, consisting of a series of three polymeric C-blocks, was compared to the polymeric baseline case to determine the effect of adding C-blocks to the serial actuator. Additionally, this case study investigated the effect of an odd number of C-blocks, rather than an even number, on the output of the series. 
- Case study 3. The third case study, consisting of a series of two piezoceramic C-blocks, served as the baseline for the piezoceramic prototypes. This series of two was again the simplest configuration containing multiple C-blocks, and thus was compared to the polymeric baseline to study the effect of different material on the output characteristics.

- Case study 4. The fourth case study, consisting of a series of four piezoceramic C-blocks, investigated the effect of the introduction of larger numbers of C-blocks. Additionally, to determine the effect of thickness, the total thickness of the C-block for the fourth case study was decreased.

- Case study 5. The fifth case study, consisting of a series of eight piezoceramic C-blocks, investigated the effect of an even greater numbers of C-blocks in series. Additionally, the total thickness and width of the C-block was changed for this case study to further examine the effect of geometric parameters.

For each of these case studies, this section describes how prototypes were fabricated, the experimental procedure used, and the experimental results.

\subsection{Prototype fabrication}

All C-blocks were fabricated as unimorphs because the piezoelectric material is maintained in compression while the metallic substrate is in tension (Brei et al 1996). Prototypes made from the two materials were fabricated using slightly different procedures.

3.1.1. PVdF polymeric case study prototypes. The polymeric prototypes were fabricated from PVdF film manufactured by AMP Incorporated. The film was preelectroded with a silver electrode and covered with a protective coating. To fabricate the polymeric actuators, each film was epoxied to alternating aluminum substrates using an Insulcast 501 epoxy manufactured by Permagile Industries. The bonded film was wrapped around dowels in alternating directions as shown in figure 4(a) and the epoxy was allowed to cure. The film was removed from the dowels and secured between glass slides. Electrodes were attached to the film, using copper tape, to form the final prototypes (figure 4(b)). Parameters for example polymeric prototypes used for case studies 1 and 2 are given in table 1 .

3.1.2. PZT piezoceramic case study prototypes. Piezoceramic prototypes were fabricated from circular PZT-5H piezoceramic tubes, manufactured by Morgan Matroc Electro Ceramics Division. The inner and outer radii of the tubes were pre-plated with a silver electrode a few micrometres thick. To fabricate the piezoceramic actuator, each tube was placed in a fixture (figure $5(a)$ ), and cut into two semicircular sections using a diamond saw. A steel strip was formed into an S-shape (figure 5(b)), to conform to the inner diameter of the piezoceramic tubes, with loops in the steel equal to the number of C-blocks in the final prototype. This steel strip formed the backbone of the C-block actuator. The piezoceramic material was epoxied to the steel with an Insulcast 501 epoxy. After the epoxy had cured, the individual piezoceramics were jumpered together to form the final prototype (figure 5(c)). Parameters for the example piezoceramic prototypes used in case studies 3,4 , and 5 are given in table 1 .

\subsection{Experimental procedure}

All of the prototypes were tested using the forcedeflection experimental set-up shown in figure 6 . Each prototype was securely clamped in a vise and connected to an Oregon Electronics Model D4 direct current (DC) voltage supply which was monitored with a Fluke multimeter. The force output of the C-block was measured using a Cooper Instruments LPM600 series force probe mounted on a precision Newport stage. Two sizes of force probe were used, a $5 \mathrm{~g}$ unit for the polymeric prototypes and a $2 \mathrm{~kg}$ unit for the piezoceramic prototypes.

For all prototypes, the same procedure was used to determine the force-deflection performance. The input DC voltage to the prototype was set to a constant input level. The position of the stage was altered until the force probe contacted the tip of the C-block, and the position of the tip of the C-block was recorded. The position of the stage was then incremented, with the position and force recorded at each increment. After each run, the voltage level was incremented and this procedure was repeated for each new voltage level. Voltage levels of 100, 200, 300, and $400 \mathrm{~V}$ were used for the polymeric prototypes; the $400 \mathrm{~V}$ level corresponded to $26 \%$ of the maximum allowable voltage for this material. Voltage levels of 50,100 , and $150 \mathrm{~V}$ were used for the piezoceramic prototypes; the $150 \mathrm{~V}$ level corresponded to $37 \%$ of the maximum allowable voltage for the third and fourth case studies and $45 \%$ of the maximum allowable voltage for the fifth case study.

\subsection{Experimental results}

The results from the experiments, along with the theoretical model (8) are plotted in figure 7 for polymeric case studies and in figure 8 for the piezoceramic case studies. The experimentally determined blocked force, $F_{b}$, and free deflection, $\Delta_{f}$, for each prototype at each voltage level are given in table 2. Also given in the table is the experimentally determined C-block stiffness, $k$, found by fitting a least-squares best-fit line to the experimental data.

Although by no means representing the entire possible design space, the C-block prototypes tested did deliver a wide range of performance. The maximum free deflection obtained ranged from $10.1 \mu \mathrm{m}$ to $1360 \mu \mathrm{m}$, and the maximum blocked force ranged from $7.30 \mathrm{mN}$ to $9.16 \mathrm{~N}$. The stiffness of the C-block ranged more dramatically, from about $5.3 \mathrm{~N} \mathrm{~m}^{-1}$ to about $460 \mathrm{kN} \mathrm{m}^{-1}$. This variability was accomplished by varying the size and material of the C-block actuators along with the serial architectural configuration parameter. This architectural parameter is very important because it allows the deflection to be modified independently of the force. This is not possible in straight benders. The availability of both geometric parameters, such as width, radius, and thickness; architectural configuration parameters such as the 


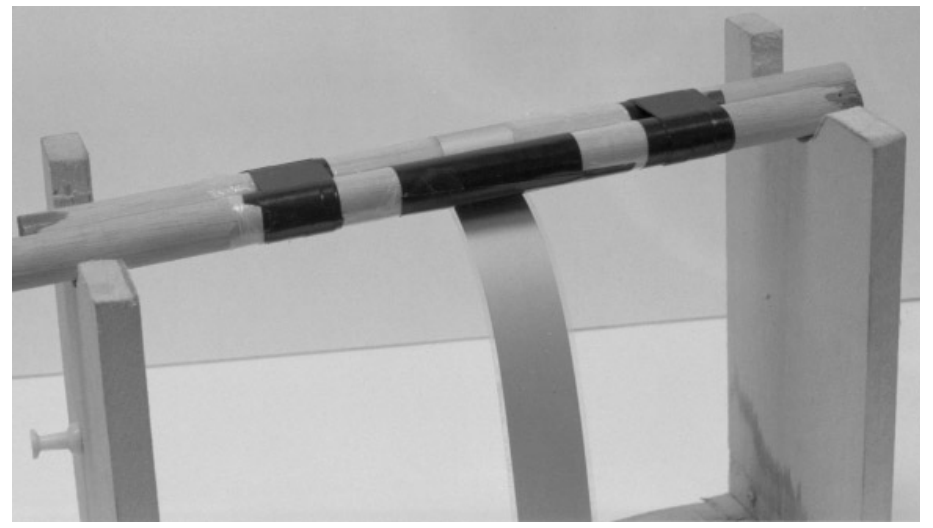

(a)

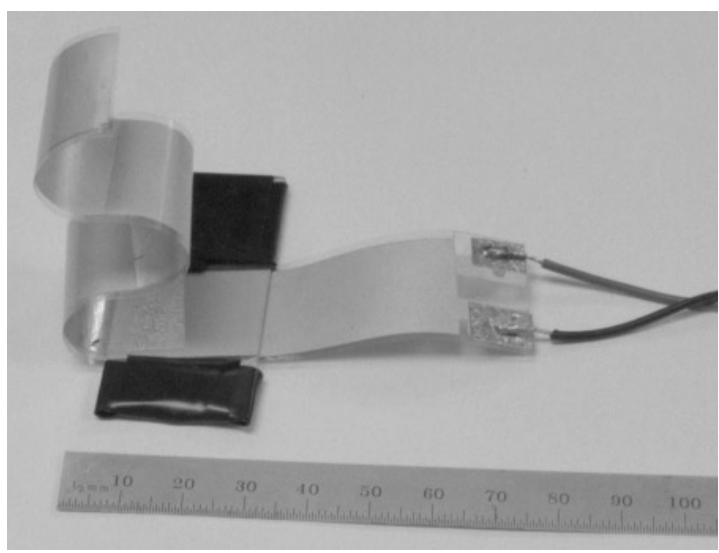

(b)

Figure 4. Fabrication procedure for polymeric prototypes. (a) The PVdF film is bonded to alternating aluminum substrates and wrapped around a dowel. (b) After curing, the polymeric film is removed from the dowel, secured between glass slides, and attached to electrodes.

number in series; and the resultant significant increase in the breadth of possible actuators, aids considerably in tailoring the actuator output to a given application and package constraint.

As table 2 shows, the results from all experiments correlate very well with the theoretical model. The average error for all prototypes was $4.69 \%$. A substantial proportion of this error is associated with the piezoceramic case studies, particularly with case studies three and four. This is due to the large stiffness and relatively small displacements of the piezoceramic prototypes. The measurement of these forces over the small displacements strained the precision limits of both the movable stage and the force transducer. Additionally, uncertainty in the thickness of the bonding layer contributed to the overall potential for error. The error from the polymeric prototypes was considerably less than from the piezoceramic case studies. However, due to the molding process used to fabricate these prototypes, there was some variance in the size of radii of the prototypes, and uncertainty in the measurement of these radii. These uncertainties undoubtedly have an effect on the final error for these prototypes. It is interesting to note that there is no apparent transmission loss from combining the C-blocks, and the model accurately captures C-block behavior to within $4.69 \%$, which is acceptable for many applications.

\section{Sensitivity analysis}

The wide range of experimental case studies show that the theoretical model can be applied to many different serial C-block actuators. Thus, these experimental case studies can be used to examine the effect of the design parameters on the C-block performance. The design parameters can be grouped into three categories: configuration parameters (number of C-blocks in series and parallel), material parameters, and geometric parameters.

\subsection{Configuration parameters}

To examine the effect of adding C-blocks to the series, the PVdF prototype from the second case study can be compared to the first, polymeric baseline case study. These two prototypes tested are fabricated from the same material, have the same thickness, and have radii that are quite similar. The deflection produced by the second case study prototype (figure $7(b)$ ) is $1359 \mu \mathrm{m}$, as compared to about $813 \mu \mathrm{m}$ produced by the first case study prototype (figure $7(a)$ ). This represents a deflection increase of nearly $100 \%$ with the additional C-block in series. However, the output force produced by these two prototypes, $7.30 \mathrm{mN}$ and $7.36 \mathrm{mN}$, is nearly the same. The difference can be attributed to the small differences in the radii and bond thickness. Thus, it can be seen that the addition of C-blocks in series will 


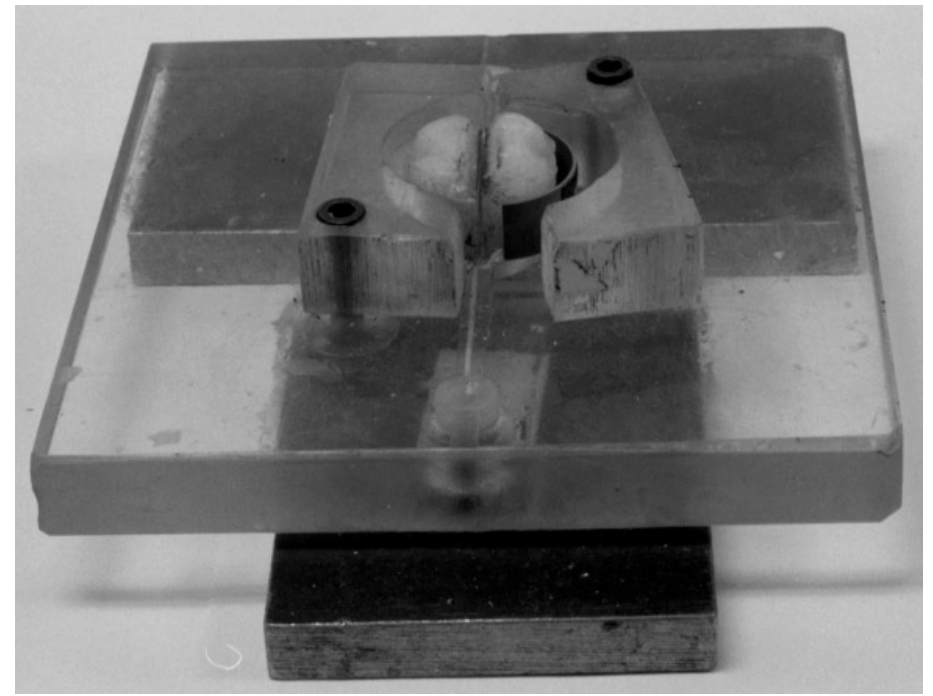

(a)

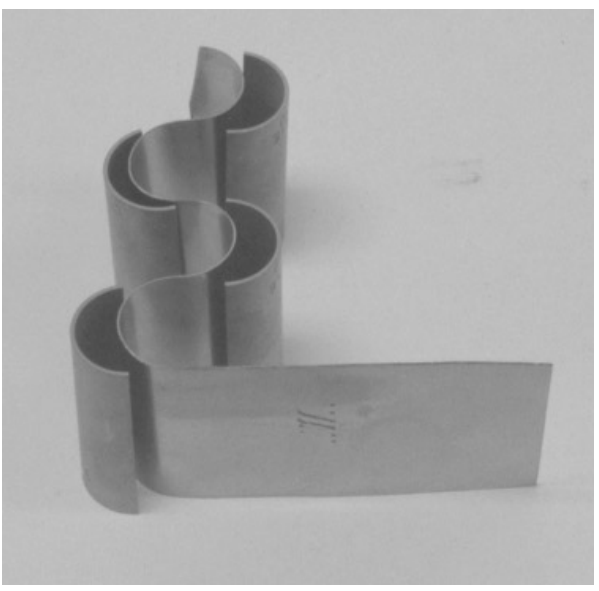

(b)

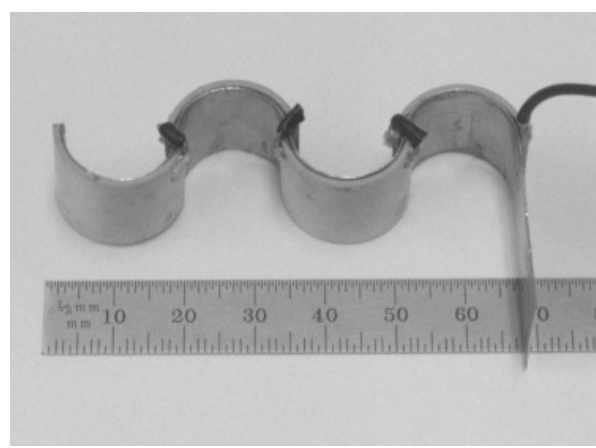

(c)

Figure 5. Fabrication procedure for piezoceramic prototypes. (a) PZT circular tubes are placed in a cutting fixture and cut into semicircles on a diamond saw. (b) A steel substrate is bent to conform to the inner diameter of the piezoceramic. $(c)$ The steel is bonded to the piezoceramic and electrode wires are soldered on to complete the prototype.

Table 1. Description of case studies. Five case studies were fabricated and tested which consisted of actuators with different serial, geometric and material parameters.

\begin{tabular}{llllllcc}
\hline $\begin{array}{l}\text { Case } \\
\text { study }\end{array}$ & Material & $\begin{array}{l}\text { No in } \\
\text { Series }\end{array}$ & $\begin{array}{l}\text { Outside } \\
\text { radius }(\mathrm{mm})\end{array}$ & Width $(\mathrm{mm})$ & $\begin{array}{l}\text { Piezo } \\
\text { thickness }(\mu \mathrm{m})\end{array}$ & $\begin{array}{l}\text { Substrate } \\
\text { thickness }(\mu \mathrm{m})\end{array}$ & $\begin{array}{l}\text { Total } \\
\text { thickness }(\mu \mathrm{m})\end{array}$ \\
\hline 1 & PVdF Polymeric & 2 & 11.0 & 22.0 & 52 & 25 & 139 \\
2 & PVdF Polymeric & 3 & 10.8 & 22.0 & 52 & 25 & 139 \\
3 & PZT Ceramic & 2 & 9.53 & 16.8 & 1000 & 710 & 1890 \\
4 & PZT Ceramic & 4 & 9.53 & 16.8 & 1000 & 460 & 1640 \\
5 & PZT Ceramic & 8 & 10.0 & 38.1 & 840 & 460 & 1480 \\
\hline
\end{tabular}

increase the deflection output of the actuator with no change in force output as predicted by the model. This makes it straight forward to design and use serial C-block actuators because the deflection increases linearly with the number of C-blocks in the series and the force output remains constant, independent of the number of C-blocks in the series.

\subsection{Material parameters}

One way to increase force output of C-block arrays is to use piezoceramic material rather than polymeric material.
The piezoceramic prototypes are constructed from thicker and less compliant material than the polymeric prototypes; thus, the piezoceramic prototypes have a substantially larger bending stiffness, $D$ (equation (5)), and overall stiffness, $k$ (equation (12)), as well as a greater piezoelectric moment, $M^{P}$ (equation (4)). Because of the increase in the moment, the prototype from the third case study (figure $8(a)$ ) produces $4.74 \mathrm{~N}$ of force, nearly three orders of magnitude more force output than the polymeric prototype from the first case study. However, since the bending stiffness is substantially increased, the enhanced force output comes at the expense 


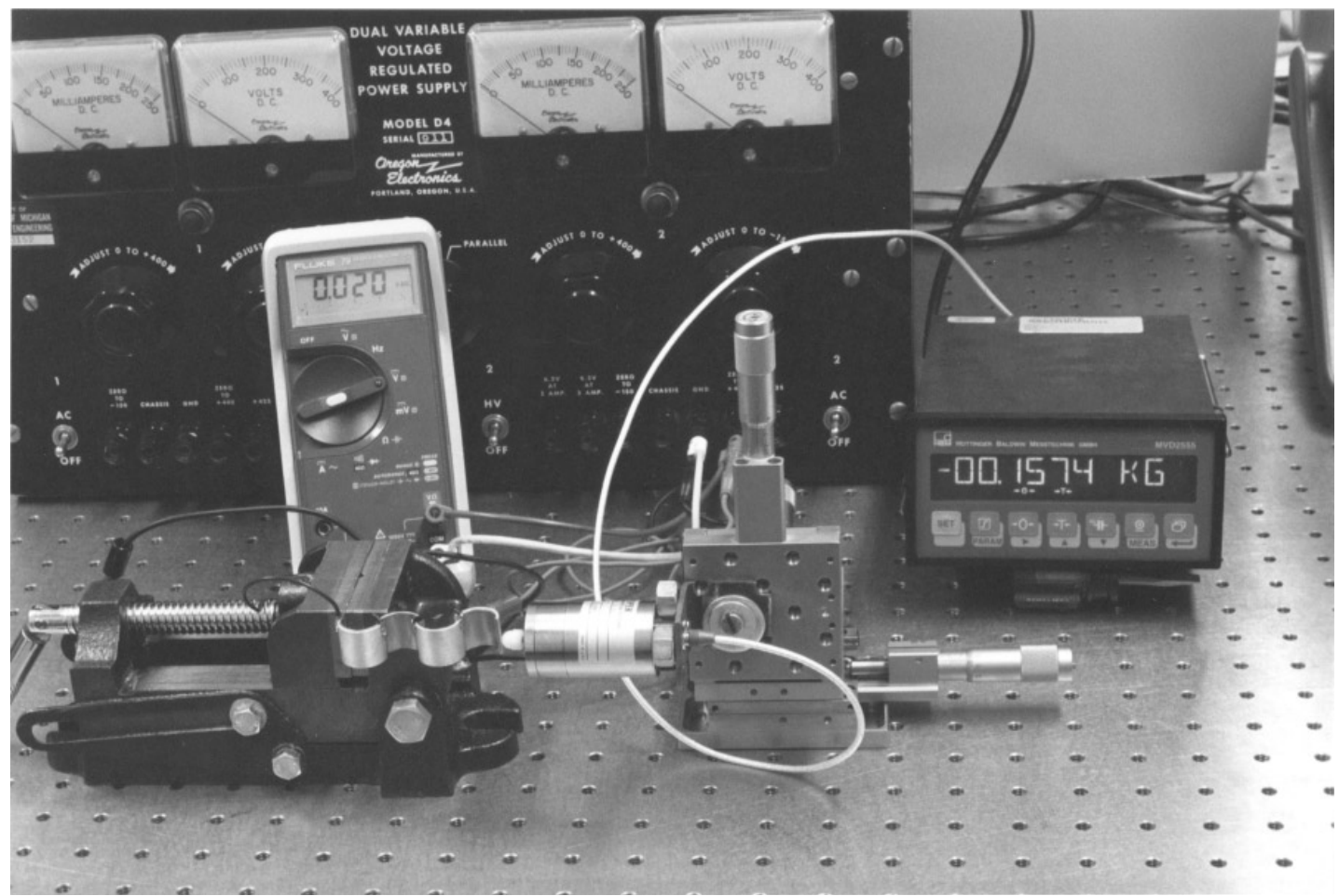

Figure 6. Experimental set-up for testing prototype C-block series actuators. Each prototype was securely clamped in a vise and connected to an Oregon Electronics Model D4 DC voltage generator. Tip force was determined using a Cooper Instruments LPM600 force probe mounted on a precision stage.

Table 2. Experimental results and error. The experimentally determined blocked force, $F_{b}$, free deflection, $\Delta_{f}$, and C-block stiffness, $k$, is given for each prototype at each voltage level tested. In addition, the average difference between the theoretically predicted force measurements and the experimentally determined force measurements is given. Average error for all prototypes is $4.69 \%$.

\begin{tabular}{|c|c|c|c|c|c|c|c|c|}
\hline \multirow[b]{2}{*}{$\begin{array}{l}\text { Case } \\
\text { study }\end{array}$} & \multirow{2}{*}{$\begin{array}{l}\text { Piezo } \\
\text { material }\end{array}$} & \multirow{2}{*}{$\begin{array}{l}\text { Exp. } \\
\text { data }\end{array}$} & \multirow{2}{*}{$\begin{array}{l}\text { Input } \\
\text { voltage } \\
\text { level } \\
\text { (V) }\end{array}$} & \multirow{2}{*}{$\begin{array}{l}\text { Blocked } \\
\text { force } F_{b}\end{array}$} & \multirow{2}{*}{$\begin{array}{l}\text { Free } \\
\text { deflection } \Delta_{f}(\mu \mathrm{m})\end{array}$} & \multirow[b]{2}{*}{ Stiffness $k$} & \multicolumn{2}{|c|}{$\begin{array}{l}\text { Difference between } \\
\text { theory and experiment }\end{array}$} \\
\hline & & & & & & & Average & $\overline{\text { Percent }}$ \\
\hline \multirow[t]{4}{*}{1} & \multirow[t]{4}{*}{$\mathrm{PVdF}$} & \multirow[t]{4}{*}{ Figure $7(a)$} & 100 & $1.81 \mathrm{mN}$ & 177 & $9.17 \mathrm{~N} \mathrm{~m}^{-1}$ & $0.18 \mathrm{mN}$ & 2.51 \\
\hline & & & 200 & $3.47 \mathrm{mN}$ & 407 & $8.68 \mathrm{~N} \mathrm{~m}^{-1}$ & $0.12 \mathrm{mN}$ & 1.58 \\
\hline & & & 300 & $5.57 \mathrm{mN}$ & 577 & $9.84 \mathrm{~N} \mathrm{~m}^{-1}$ & $0.41 \mathrm{mN}$ & 5.55 \\
\hline & & & 400 & $7.30 \mathrm{mN}$ & 813 & $8.86 \mathrm{~N} \mathrm{~m}^{-1}$ & $0.41 \mathrm{mN}$ & 5.68 \\
\hline \multirow[t]{4}{*}{2} & \multirow[t]{4}{*}{ PVdF } & \multirow[t]{4}{*}{ Figure $7(b)$} & 100 & $1.79 \mathrm{mN}$ & 360 & $5.45 \mathrm{~N} \mathrm{~m}^{-1}$ & $0.13 \mathrm{mN}$ & 1.76 \\
\hline & & & 200 & $3.68 \mathrm{mN}$ & 734 & $5.22 \mathrm{~N} \mathrm{~m}^{-1}$ & $0.19 \mathrm{mN}$ & 2.52 \\
\hline & & & 300 & $5.49 \mathrm{mN}$ & 1008 & $5.47 \mathrm{~N} \mathrm{~m}^{-1}$ & $0.19 \mathrm{mN}$ & 2.59 \\
\hline & & & 400 & $7.36 \mathrm{mN}$ & 1360 & $5.22 \mathrm{~N} \mathrm{~m}^{-1}$ & $0.30 \mathrm{mN}$ & 4.06 \\
\hline \multirow[t]{3}{*}{3} & \multirow[t]{3}{*}{ PZT } & \multirow[t]{3}{*}{ Figure $8(a)$} & 50 & $1.58 \mathrm{~N}$ & 3.27 & $447 \mathrm{kN} \mathrm{m}^{-1}$ & $0.21 \mathrm{~N}$ & 4.57 \\
\hline & & & 100 & $3.05 \mathrm{~N}$ & 6.60 & $455 \mathrm{kN} \mathrm{m}^{-1}$ & $0.22 \mathrm{~N}$ & 4.85 \\
\hline & & & 150 & $4.74 \mathrm{~N}$ & 10.1 & $478 \mathrm{kN} \mathrm{m}^{-1}$ & $0.52 \mathrm{~N}$ & 11.52 \\
\hline \multirow[t]{3}{*}{4} & \multirow[t]{3}{*}{ PZT } & \multirow[t]{3}{*}{ Figure $8(b)$} & 50 & $0.90 \mathrm{~N}$ & 5.51 & $143 \mathrm{kN} \mathrm{m}^{-1}$ & $0.14 \mathrm{~N}$ & 5.22 \\
\hline & & & 100 & $1.85 \mathrm{~N}$ & 13.3 & $139 \mathrm{kN} \mathrm{m}^{-1}$ & $0.18 \mathrm{~N}$ & 6.55 \\
\hline & & & 150 & $2.77 \mathrm{~N}$ & 21.7 & $135 \mathrm{kN} \mathrm{m}^{-1}$ & $0.23 \mathrm{~N}$ & 8.33 \\
\hline \multirow[t]{3}{*}{5} & \multirow[t]{3}{*}{ PZT } & \multirow[t]{3}{*}{ Figure $8(c)$} & 50 & $3.28 \mathrm{~N}$ & 36.9 & $88.7 \mathrm{kN} \mathrm{m}^{-1}$ & $0.21 \mathrm{~N}$ & 2.14 \\
\hline & & & 100 & $6.00 \mathrm{~N}$ & 68.5 & $89.0 \mathrm{kN} \mathrm{m}^{-1}$ & $0.77 \mathrm{~N}$ & 7.65 \\
\hline & & & 150 & $9.16 \mathrm{~N}$ & 103 & $89.0 \mathrm{kN} \mathrm{m}^{-1}$ & $0.26 \mathrm{~N}$ & 2.59 \\
\hline
\end{tabular}

of deflection performance. The piezoceramic prototype produces only $10.1 \mu \mathrm{m}$ of deflection, two orders of magnitude less than the polymeric prototype. The C-block stiffness for the third case study is about $460 \mathrm{kN} \mathrm{m}^{-1}$ compared to a stiffness of about $9.1 \mathrm{~N} \mathrm{~m}^{-1}$ for the first case study. Thus, as expected, the thinner, more compliant polymeric prototypes produce considerably more free deflection (equation (10)) and the thicker, stiffer piezoceramic prototypes produce considerably more blocked force (equation (11)).

\subsection{Geometric parameters}

The piezoceramic case studies show the effect of the combination of increasing the number of C-blocks in series 


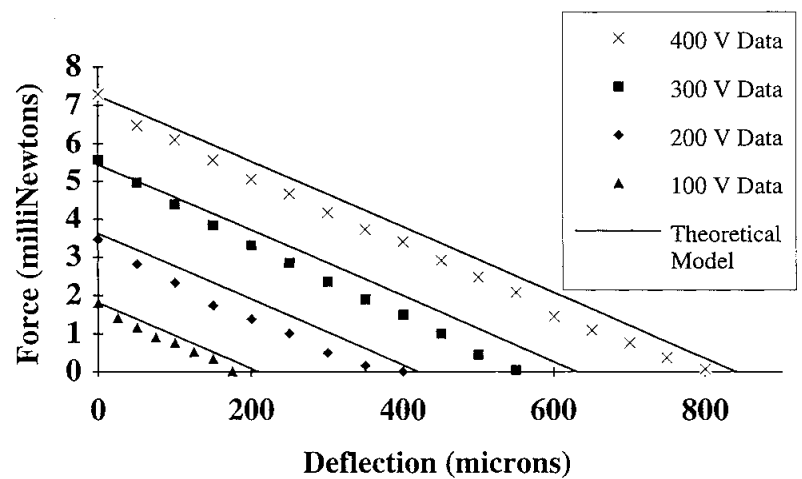

(a)

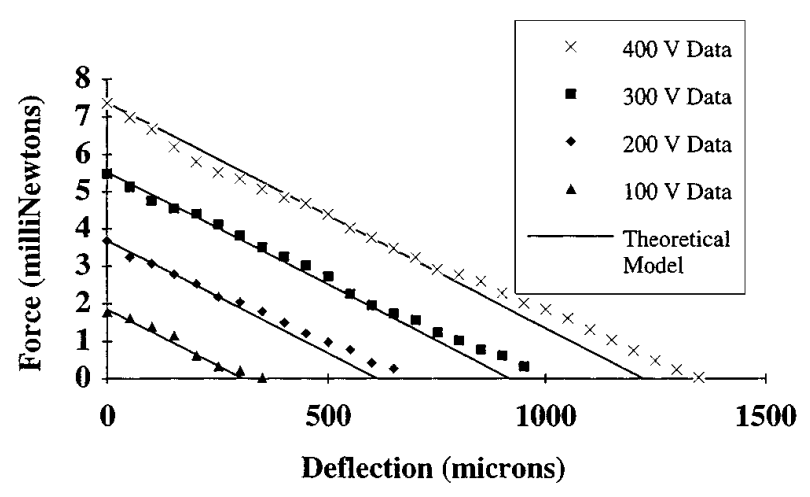

(b)

Figure 7. Experimental results for polymeric case studies. (a) Case Study 1: Series of two PVdF C-blocks of $11.0 \mathrm{~mm}$ outside radius and $129 \mu \mathrm{m}$ total thickness. (b) Case Study 2: Series of three PVdF C-blocks of $10.8 \mathrm{~mm}$ outside radius and $129 \mu \mathrm{m}$ total thickness.

and altering the geometric properties of the series. The fourth case study (figure $8(b)$ ) produces $21.7 \mu \mathrm{m}$ deflection, which is over twice the deflection of the piezoceramic baseline, because of the greater number in series. However, due to the decreased stiffness from variations in the geometric parameters, the force output of the fourth case study prototype, $2.77 \mathrm{~N}$, is slightly smaller than the force output of the baseline. Thus, the force and deflection output can be altered by changing the C-block stiffness through altering the thickness of the C-block.

The fifth case study (figure $8(c)$ ) contains eight individual C-blocks, twice as many as the fourth case study. The C-blocks in this case study are slightly thinner and considerably wider than the fourth case study. Changing the width linearly changes both the bending stiffness, $D$ (equation (5)), and the piezoelectric moment, $M^{P}$ (equation (4)). Since both parameters change, the increase in the width of this prototype increases the output force (equation (11)) without changing output deflection (equation (10)). The piezoelectric material is also thinner in the fifth case study, and thus the electric field is increased. This in turn increases the piezoelectric moment, $M^{P}$, and decreases the bending stiffness, $D$. One effect of the changes in the width, thickness, and number of C-blocks in series is to increase the output deflection to $92 \mu \mathrm{m}$. This change is due to the increase in the number of C-blocks and the decrease in thickness. The force output is also increased to $9.16 \mathrm{~N}$,

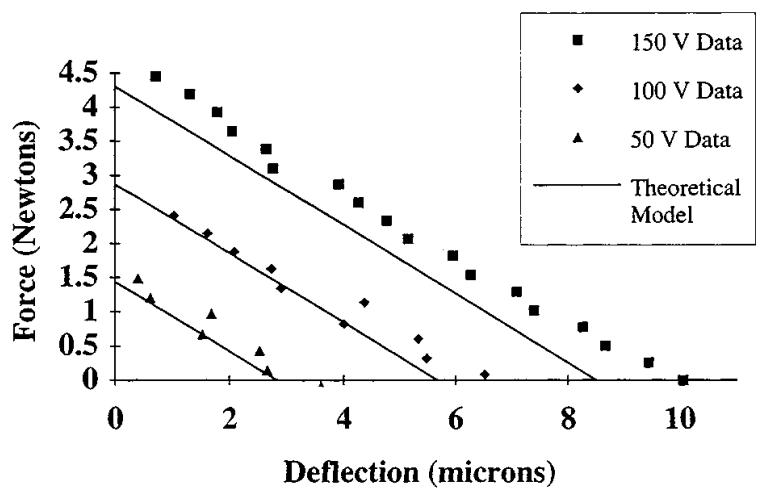

(a)

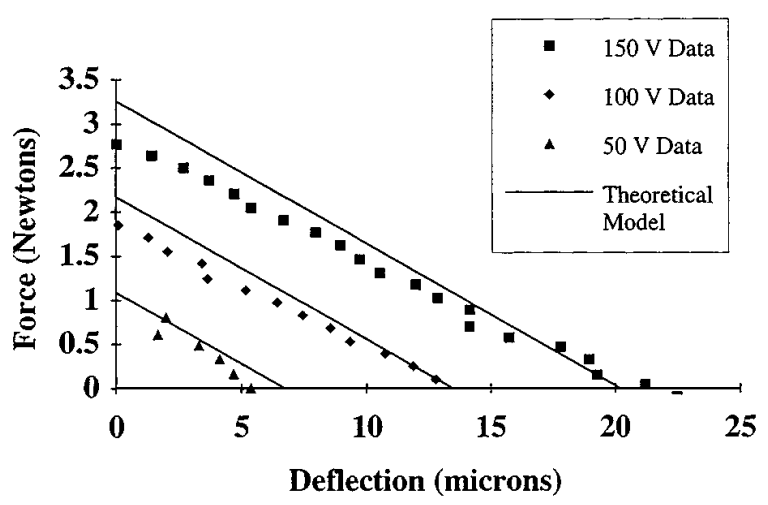

(b)

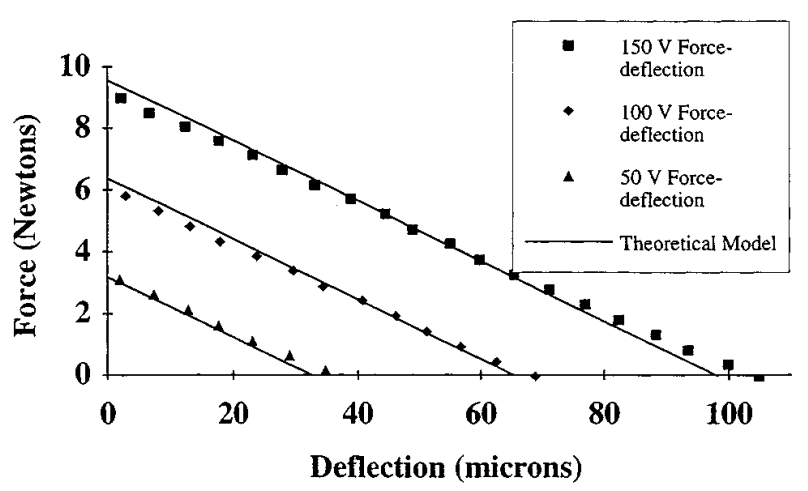

(c)

Figure 8. Experimental results for piezoceramic case studies. (a) Case Study 3: Series of two PZT-5H C-blocks of $9.53 \mathrm{~mm}$ outside radius and $1.89 \mathrm{~mm}$ total thickness. (b) Case Study 4: Series of four PZT-5H C-blocks of $9.53 \mathrm{~mm}$ outside radius and $1.64 \mathrm{~mm}$ total thickness. (c) Case Study 5: Series of eight PZT-5H C-blocks of $10.0 \mathrm{~mm}$ outside radius and $1.48 \mathrm{~mm}$ total thickness.

due to the increase in the width offsetting the decrease in the thickness to produce an overall increase in the bending stiffness, $D$ (equation (5)).

\subsection{Design of C-block architectures}

These five experimental case studies physically demonstrate the breadth of this architecture and the many design alternatives available to alter the performance characteristics of a C-block actuator. For example, to increase the deflection, the radius or number in series can be increased, or the thickness can be decreased. To increase the force, the number in parallel, the width, the thickness, or Young's 
modulus can be increased, or the radius can be decreased. One major advantage of the C-block array architecture is that increasing the number in series has no effect on the force, while increasing the number in parallel has no effect on the deflection. Thus, these configuration parameters can be used to easily tailor the performance of the architecture to application requirements, unlike many other current piezoelectric actuation architectures.

\section{Actuator architecture comparison}

The preceding sections have developed and verified the quasi-static performance model for a generic C-block actuator. Employing this model, it is useful to examine the performance of the C-block architecture in comparison to other piezoelectric actuators to determine the relative merits of the C-block. Two different methods are utilized. First, the maximum absolute performance of each architecture is compared on the basis of force, deflection, work, and stiffness capabilities. This tells an engineer if a feasible actuator that meets the application requirements exists in a specific architectural family. The second method compares the relative merit of each architecture based on normalized metrics by examining the strain output (displacement per package length), effective stress (force per package area perpendicular to its length), and ultimately work per actuator volume. It should be noted that even though the effective stress has units of stress, this metric does not necessarily correspond to the stress within the actuator. This second method not only aids in assessing feasibility, but it also gives a measure of how effective an architecture will be given particular package constraints. To specify an actuator for a particular application, both of these methods should be used, so that the architecture chosen is able to meet the required force and deflection requirements and is the most effective actuator for a given application space.

This section details the comparisons among six actuator architectures: leveraged and unleveraged stacks (figure 1(a)), Moonies (figure 1(c)), Cymbals (figure $1(d)$ ), straight benders (figure 2(a)), and CRESCENT/Rainbow/THUNDER type actuators (figure 2(c)). The $\mathrm{X}$-frame actuator (figure $1(b)$ ) was considered to be a leveraged stack, and tapered benders (figure 2(b)) were classified with straight benders. Rainbow and THUNDER actuators were considered together, since their performance is very similar (Wise 1998). For comparison, monolithic plates of piezoelectric material actuated in the $d_{33}$ and $d_{31}$ modes are included. To perform the comparison based on architecture only, each architecture was assumed to be fabricated from the same material: an EBL16 high-performance PZT piezoelectric material (Staveley), which delivers a maximum of $1.2 \times 10^{-3}$ strain and around $60 \times 10^{-6} \mathrm{~Pa}$ of apparent stress when trained in one direction.

\subsection{Absolute metrics}

The first set of comparison metrics for actuator architectures is the force and displacement output available from each type of actuator. For C-blocks, the relationship between force and deflection (equation (8)) was used to determine performance limits for the $\mathrm{C}$-block architecture. A maximum actuator size of $0.4 \mathrm{~m}$ long and $0.2 \mathrm{~m}$ wide in each direction with a radius to thickness ratio between 5 and 100 was assumed. This represents an actuator size that was deemed to be on the edge of the feasible manufacturing design space. C-block actuators larger than the given size are difficult to fabricate due to the complexity of the array and/or the size of the individual C-blocks within the array, while C-blocks outside of the radius to thickness ratio are either too thick to be accurately modeled as a thin beam, or too thin to be easily manufactured. Using these assumptions, the maximum analytical simultaneous force and displacement was calculated for a distributed array of C-blocks.

The force and displacement of C-block actuators was compared to that from other actuator architectures. These numbers depend on the relative leveraging capability of each architecture, the losses associated with the leveraging scheme, and the practical limitations on what can be fabricated. Figure 9 shows the total force and deflection output available from each type of actuator architecture for ceramic materials. This figure is a modified version of the graph appearing in Near (1996) with additional information as cited in the figure caption. In addition to the graphic given in figure 9, the maximum force, displacement, work, and stiffness range available from each architecture are given in table 3. It is important to note that maximum values of force and deflection given for a particular architecture cannot be obtained from the same actuator, but rather represent the performance limits that can be obtained from an actuator by altering the architecture parameters.

It can be seen from figure 9 that the C-block is competitive with other architectures across a wide range of performance targets. As expected, the C-block does not produce as much force as the biggest stack or as much deflection as a series of thin THUNDER actuators; instead, the C-block gives performance in the midrange. C-blocks compare very well with straight benders, which are currently one of the most popular piezoelectric actuator architectures (Lee et al 1998). Not only are C-blocks capable of greater force output than a straight bender, but they are also capable of a greater deflection output, primarily due to the array structure of C-block architectures. Finally, although other architectures such as the leveraged stack produce greater combinations of force and deflection than the C-block, the C-block is still competitive across a wide application space, and may be preferable due to its greater work per volume output, which is discussed in the next section.

\subsection{Normalized metrics}

To further differentiate actuator architectures, the architectures are compared using a method that examines the normalized metrics of actuator work per volume, strain and effective stress. This helps to determine the most effective actuator among those whose absolute performance is the same. The strain is defined as the maximum (free) deflection divided by the actuator length. For the C-block, the strain is calculated as the free deflection (equation (10)) divided by the length of the array, $2 n R_{n}$. The effective stress is defined as the maximum (blocked) force divided by the total area of the actuator 


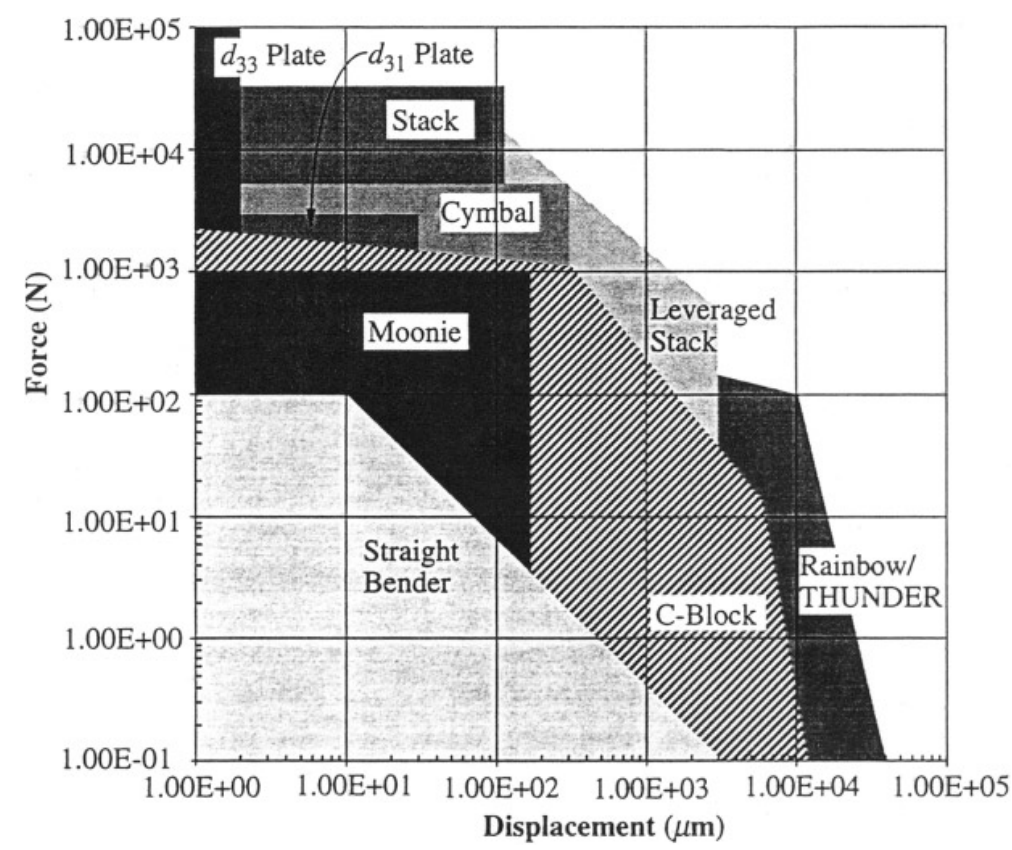

Figure 9. Comparison of C-blocks to other actuator architectures for force and deflection output. Ceramic C-blocks are compared to other actuator architectures for force and deflection output. Other architectures include $d_{33}$ plates, $d_{31}$ plates, stacks, leveraged stacks, straight benders, Cymbals, Moonies, and Rainbow/THUNDER-type actuators (adapted from Near 1996 with additional information taken from Dogan et al 1997, Face International 1997, Giurgiutiu et al 1996, Prechtl and Hall 1997 and Steel et al 1978).

Table 3. Comparison of C-blocks to other actuator architectures. Each actuator architecture is compared to determine the maximum force, displacement, work, and stiffness range attainable by the architecture. Additionally, the maximum relative amount of strain, effective stress, and work per actuator volume is given as a fraction of the output attainable by a $d_{33}$ plate. Information in this table is adapted from Near (1996).

\begin{tabular}{|c|c|c|c|c|c|c|c|}
\hline \multirow[b]{2}{*}{$\begin{array}{l}\text { Actuator } \\
\text { architecture }\end{array}$} & \multirow{2}{*}{$\begin{array}{l}\text { Maximum } \\
\text { force } \\
\text { (N) }\end{array}$} & \multirow{2}{*}{$\begin{array}{l}\text { Maximum } \\
\text { deflection } \\
(\mu \mathrm{m})\end{array}$} & \multirow{2}{*}{$\begin{array}{l}\text { Maximum } \\
\text { work } \\
(\mathrm{mJ})\end{array}$} & \multirow{2}{*}{$\begin{array}{l}\text { Stiffness } \\
\text { range } \\
\left(\mathrm{MN} \mathrm{m}^{-1}\right)\end{array}$} & \multicolumn{3}{|c|}{ Relative to $d_{33}$ plate } \\
\hline & & & & & Strain & $\begin{array}{l}\text { Effective } \\
\text { stress }\end{array}$ & $\begin{array}{l}\text { Work per } \\
\text { actuator volume }\end{array}$ \\
\hline$d_{33}$ plate & 100000 & 2 & 100 & $5000-100000$ & 1.00 & 1.00 & 1.00 \\
\hline$d_{31}$ plate & 3000 & 30 & 45 & $100-3000$ & 0.40 & 0.65 & 0.26 \\
\hline Stack & 35000 & 120 & 45 & $100-35000$ & 1.00 & 0.27 & 0.27 \\
\hline $\begin{array}{l}\text { Leveraged } \\
\text { stack }\end{array}$ & 10000 & 3000 & 900 & $0.1-1000$ & $1-100$ & $0.09-0.0009$ & 0.09 \\
\hline Moonie & 1000 & 200 & 100 & $0.3-100$ & $5-20$ & $0.0018-0.00045$ & 0.009 \\
\hline Cymbal & 5000 & 400 & 1000 & $0.1-100$ & $15-40$ & $0.006-0.0025$ & 0.09 \\
\hline $\begin{array}{l}\text { Straight } \\
\text { bender } \\
\text { Rainbow/ }\end{array}$ & 100 & 3000 & 0.5 & $0.2-1$ & $10-500$ & $0.015-0.0003$ & 0.15 \\
\hline THUNDER & 500 & 30000 & 500 & $0.01-3$ & $25-50000$ & $0.0037-0.000002$ & 0.083 \\
\hline C-block & 2200 & 12600 & 165 & $0.001-100$ & $6.56-131$ & $0.0244-0.00122$ & 0.16 \\
\hline
\end{tabular}

perpendicular to the applied force. For the C-block, this is the blocked force (equation (11)) divided by the average cross sectional area, i.e. the area such that $2 n R_{n} A$ is equal to the entire volume of the actuator. These quantities can be used to determine the actuator length and area required to produce target displacement and force. The work per actuator volume is one half of the product of strain and effective stress (Giurgiutiu et al 1996).

For each actuator architecture, the maximum possible combinations of strain and effective stress were calculated; this is represented in figure 10 by the solid lines at the top of each shaded area. The information used in this figure was compiled from the references given in the figure caption. Depending on the design of the particular actuator, the work per volume is variable, resulting in a range of work per actuator volume numbers and thus a range of possible combinations of strain and effective stress. The full range of performance for each actuator are denoted by shaded areas on the graph. To aid in comparison of architectures, table 3 presents the strain for each actuator as a fraction of the strain available from a $d_{33}$ plate; similarly, the effective stress and work per actuator volume are given as a proportion of the same metric available from a $d_{33}$ plate.

The most important aspect to note in figure 10 is that the C-block produces more work per volume than the other midrange and internally-leveraged architectures. Thus, even though other architectures, such as leveraged stacks, Cymbals, Rainbows and THUNDERs, have regions where 


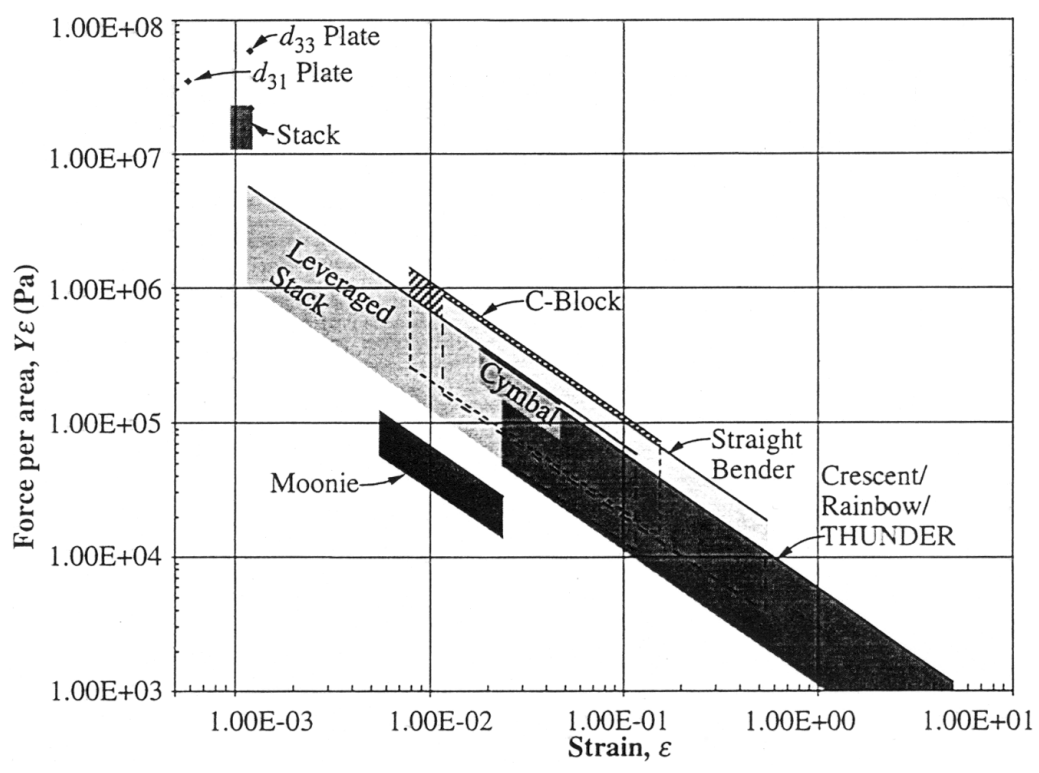

Figure 10. Comparison of C-block to other actuator architectures for strain and effective stress output. C-blocks are compared to other actuator architectures for strain output, $\varepsilon$, and effective stress, $Y \varepsilon$, assuming a high-performance PZT material. Other architectures include $d_{33}$ plates, $d_{31}$ plates, stacks, leveraged stacks, straight benders, Cymbals, Moonies, and Rainbow/THUNDER-type actuators. The solid line represents the maximum attainable for each architecture, while the shaded areas represent values more commonly obtained. The product of strain and apparent force per area, $Y \varepsilon^{2}$, is proportional to the work stored in the actuator per unit material volume. The information in this figure was gathered from Barron et al (1996), Chandran et al (1997), Dogan et al (1997), Face International (1997), Giurgiutiu et al (1996), Haertling (1994), Kugel et al (1997), Near (1996), Paine and Chaudhry (1996), and Tzou (1989).

the absolute force-deflection performance may be better, in those regions where a C-block is feasible it is the best choice due to its higher available work per actuator volume. Thus, C-blocks can perform more work than other actuators fabricated from the same amount of material; alternatively, the same amount of work can be performed by C-blocks containing less material. In addition, it is important to note that the C-block architecture produces a constant work per volume throughout its operation range, unlike architectures such as the leveraged stack where the operating losses increase with a greater strain output. Although the C-block does not produce the work per volume of monolithic plates or the stack architecture, these architectures are only applicable in the lower strain range.

\section{Conclusion}

This paper has presented the characterization of the quasistatic force-deflection behavior for generic C-block actuator array architectures. A theoretical model was derived that predicts the force-deflection behavior of a C-block array formed from any number of individual C-blocks in parallel and/or series, which can be constructed from any type of piezoelectric material, polymeric or ceramic. Five experimental case studies were examined, with prototypes fabricated out of both piezoelectric polymeric and ceramic material. Each prototype was experimentally tested across a range of voltages to verify the force-deflection behavior predicted by the model. The results were studied to gain insight into the model sensitivity and establish design guidelines. In addition, the quasi-static model developed was used to compare the performance of the C-block architecture to other common piezoelectric actuator architectures. Even though this comparison study is by no means exhaustive, it does indicate that there is a useful niche filled by this new class of actuation technology. From this investigation, it can be concluded that:

- The average difference between the theoretically predicted force measurements and the experimentally determined force measurements for all prototypes was $4.69 \%$.

- For the C-block prototypes tested, the maximum free deflection obtained ranged from $10.1 \mu \mathrm{m}$ to $1360 \mu \mathrm{m}$, the maximum blocked force ranged from $7.30 \mathrm{mN}$ to $9.16 \mathrm{~N}$, and the stiffness of the C-block ranged from about $5.3 \mathrm{~N} \mathrm{~m}^{-1}$ to about $460 \mathrm{kN} \mathrm{m}^{-1}$. The C-block actuator array architecture is predicted to provide up to $12.6 \mathrm{~mm}$ of deflection or $2200 \mathrm{~N}$ of force.

- The displacement output of the C-block actuator array is linearly proportional to the number of C-blocks in series, and does not depend on the number in parallel. Likewise, the force output of the serial C-block actuator array is linearly proportional to the number of C-blocks in parallel, and does not depend on the number in series.

- Changing the piezoelectric material produces changes in performance due to different material stiffness, piezoelectric constant, and thickness. Increasing the stiffness of the material linearly increases the force output without affecting the deflection. Increasing the piezoelectric constant linearly increases both the output force and deflection.

- Increasing the width of the C-block actuator will linearly increase the force output without changing the output deflection, while increasing the thickness of the C-block will both cubically increase the output force and quadratically decrease the deflection. 
- The C-block produces the greatest work per volume of higher displacement actuators, including straight benders, Rainbows, THUNDERs, Cymbals, Moonies, and leveraged stacks.

- The C-block architecture produces more force and more deflection than the straight bender architecture, which is currently one of the most popular piezoelectric actuator architecture.

Therefore, the C-block actuator is a promising alternative actuator architecture for many smart structures applications that require specific force and deflection performance. Because of the tailorability of the array structure, C-blocks can be fabricated with a range of different force and deflection performance characteristics by altering the geometric, material and architectural configuration parameters. Additionally, the C-block architecture compares well in work per volume to other architectures, having a higher work per volume than all other actuators with reasonable deflection amplification. Thus, because of these advantages of the C-block architecture, this actuator architecture is a good candidate for numerous smart structures applications.

\section{Acknowledgment}

This material is based upon work supported by the US Army Research Office under grant number DAAH04-96-1-0186.

\section{References}

Bamford R, Kuo C P, Glaser R and Wada B K 1995 Long stroke precision PZT actuator AIAA/ASME/ASCE/AHS/ASC Structures, Structural Dynamics, and Materials Conf.-Collection of Technical Papers (New York: AIAA) pp 3278-84

Barron B W, Li G and Haertling G H 1996 Temperature dependent characteristics of Cerambow actuators IEEE Int. Symp. on Applications of Ferroelectrics Part 1 (Piscataway, NJ: IEEE) pp 305-8, 96CH35948

Ben-Zeev O and Chopra I 1996 Advances in the development of an intelligent helicopter rotor employing smart trailing-edge flaps Smart Mater. Struct. 5 11-25

Brei D, Ervin J D, and Moskalik A J 1996 Deflection-voltage performance of asymmetrically activated piezoelectric C-block actuators Smart Structures and Materials 1996: Smart Structures and Integrated Systems (Bellingham, WA: SPIE) pp 276-86

Chandran S, Kugel V D and Cross L E 1997 CRESCENT: A novel piezoelectric bending actuator Smart Structures and Materials 1997: Smart Structures and Integrated Systems (Bellingham, WA: SPIE) pp 461-9

Dogan A, Uchino K and Newnham R E 1997 Composite piezoelectric transducer with truncated conical endcaps 'cymbal' IEEE Trans. Ultrasonics, Ferroelectrics, Frequency Control 44 597-605

Face International 1997 THUNDER Actuators and Sensors [brochure] available from Face International, 427 W. 35th Street, Norfolk, VA 23508, USA
Giurgiutiu V, Chaudhry Z and Rogers C A 1995, Stiffness issues in the design of ISA displacement amplification devices: case study of a hydraulic displacement amplifier Smart Structures and Materials 1995: Smart Structures and Integrated Systems (Bellingham, WA: SPIE) pp 105-19

Giurgiutiu V, Rogers C A and Chaudhry Z 1996 Energy-based comparison of solid-state induced-strain actuators J. Intell. Mater. Syst. Struct. 7 4-14

Haertling G H 1994 Ultra-high-displacement actuator Am. Ceram. Soc. Bull. 73 93-6

Hall S R and Prechtl E F 1996 Development of a piezoelectric servoflap for helicopter rotor control Smart Mater. Struct. 5 26-34

Kugel V D, Chandran S and Cross L E 1997 Comparative analysis of piezoelectric bending-mode actuators Smart Structures and Materials 1997: Smart Materials Technologies (Bellingham, WA: SPIE) pp 70-80

Lee C K, Chang S H and Chang, P-Z 1998 Miniature piezoelectric actuators: Design concept, fabrication and performance evaluation Smart Mater. Struct. 7 312-26

Moskalik A J and Brei D 1997a Frequency-amplitude response of individual polyvinylidene fluoride piezoelectric C-block actuators Smart Structures and Materials 1997: Smart Structures and Integrated Systems (Bellingham, WA: SPIE) pp 482-95

_ 1997b Quasi-static behaviour of individual C-block piezoelectric actuators J. Intell. Mater. Syst. Struct. 8 571-87

-1998 Parametric investigation of the deflection performance of serial piezoelectric C-block actuators J. Intell. Mater. Syst. Struct. $9223-31$

Near C D 1996 Piezoelectric actuator technology Smart Structures and Materials 1996: Smart Structures and Integrated Systems (Bellingham, WA: SPIE) pp 246-58

Onitsuka K, Dogan A, Tressler J F, Xu Q, Yoshikawa S and Newnham R E 1995 Metal-ceramic composite transducer, the 'moonie' J. Intell. Mater. Syst. Struct. 6 447-55

Paine J S N and Chaudhry Z 1996 The impact of amplification on efficiency and energy density of induced strain actuators Proc. ASME Aerospace Division (New York: ASME) pp 511-16

Prechtl E F and Hall S R 1997 Design of a high efficiency discrete servo-flap actuator for helicopter rotor control Smart Structures and Materials 1997: Smart Structures and Integrated Systems (Bellingham, WA: SPIE) pp 158-82

Samak D K and Chopra I 1996 Design of high force, high displacement actuators for helicopter rotor blade control Smart Mater. Struct. 5 58-67

Spencer B T and Chopra I 1996 Design and testing of a helicopter trailing edge flap with piezoelectric stack actuators, Smart Structures and Materials 1996: Smart Structures and Integrated Systems (Bellingham, WA: SPIE) pp 120-31

Staveley (no date) EBL Ceramic Tubes for Ultraprecise Positioning Applications [brochure] available from Staveley Sensors, 91 Prestige Park Circle, East Hartford CT 06108

Steel M R, Harrison F and Harper P G 1978 The piezoelectric bimorph: An experimental and theoretical study of its quasistatic response J. Phys. D: Appl. Phys. 11 979-89

Tzou H S 1989 Development of a light-weight robot end-effector using polymeric piezoelectric bimorph Proc. 1989 Int. Conf. Robotics and Automation (Washington, DC: IEEE Computer Society) pp 1704-9, 89CH2750

Wise S A 1998 Displacement properties of RAINBOW and THUNDER piezoelectric actuators Sensors Actuators A 69 $33-8$ 